\title{
Late symptoms in long-term gynaecological cancer survivors after radiation therapy: a population-based cohort study
}

\author{
H Lind ${ }^{*, 1}$, A-C Waldenström ${ }^{2,3}$, G Dunberger', M al-Abany ${ }^{1,4}$, E Alevronta', K-A Johansson ${ }^{5}$, C Olsson ${ }^{2,6}$, \\ T Nyberg', U Wilderäng ${ }^{2}$, G Steineck ${ }^{1,2}$ and E Åvall-Lundqvist ${ }^{1,7}$ \\ 'Clinical Cancer Epidemiology, Department of Oncology and Pathology, Karolinska Institutet, Stockholm, Sweden; '²Division of Clinical Cancer \\ Epidemiology, Department of Oncology, Institute of Clinical Sciences, Sahlgrenska Academy at University of Gothenburg, Gothenburg, Sweden; \\ ${ }^{3}$ Department of Oncology, Sahlgrenska University Hospital, Gothenburg, Sweden; ${ }^{4}$ Department of Medical Physics, Karolinska University Hospital, \\ Stockholm, Sweden; ${ }^{5}$ Department of Radiation Physics, Institute of Clinical Sciences, Sahlgrenska Academy at University of Gothenburg, Gothenburg, \\ Sweden; ${ }^{6}$ Department of Radiation Physics, Institute of Clinical Sciences, Sahlgrenska Academy at University of Gothenburg, Gothenburg, Sweden; \\ ${ }^{7}$ Department of Gynecologic Oncology, Karolinska University Hospital, Stockholm, Sweden
}

\begin{abstract}
BACKGROUND: We surveyed the occurrence of physical symptoms among long-term gynaecological cancer survivors after pelvic radiation therapy, and compared with population-based control women.

METHODS: We identified a cohort of 789 eligible gynaecological cancer survivors treated with pelvic radiation therapy alone or combined with surgery in Stockholm or Gothenburg, Sweden. A control group of 478 women was randomly sampled from the Swedish Population Registry. Data were collected through a study-specific validated postal questionnaire with 35I questions concerning gastrointestinal and urinary tract function, lymph oedema, pelvic bones and sexuality. Clinical characteristics and treatment details were retrieved from medical records.

RESULTS: Participation rate was 78\% for gynaecological cancer survivors and 72\% for control women. Median follow-up time after treatment was 74 months. Cancer survivors reported a higher occurrence of symptoms from all organs studied. The highest age-adjusted relative risk (RR) was found for emptying of all stools into clothing without forewarning (RR I2.7), defaecation urgency (RR 5.7), difficulty feeling the need to empty the bladder (RR 2.8), protracted genital pain (RR 5.0), pubic pain when walking indoors (RR 4.9) and erysipelas on abdomen or legs at least once during the past 6 months (RR 3.6). Survivors treated with radiation therapy alone showed in general higher rates of symptoms.

CONCLUSION: Gynaecological cancer survivors previously treated with pelvic radiation report a higher occurrence of symptoms from the urinary and gastrointestinal tract as well as lymph oedema, sexual dysfunction and pelvic pain compared with non-irradiated control women. Health-care providers need to actively ask patients about specific symptoms in order to provide proper diagnostic investigations and management.
\end{abstract}

British Journal of Cancer (20II) I 05, 737-745. doi:I0.1038/bjc.20II.3I5 www.bjcancer.com

Published online 16 August 201 I

(c) 201 I Cancer Research UK

Keywords: gynaecological cancer survivors; radiation therapy; long-term side-effects; pelvic

With increasing numbers of long-term gynaecological cancer survivors, the prevention and alleviation of late side effects after treatment have become a priority. A significant number of these survivors have been treated with pelvic radiation therapy. Radiation therapy may induce pathophysiological changes in all normal tissue or organs within the irradiated volume, which in some cases will lead to symptoms negatively affecting daily activities and quality of life. Although some late effects from normal tissues have been extensively explored (Eifel et al, 1995; Grigsby et al, 1995; Creutzberg et al, 2001; Nout et al, 2009), others have been less characterised (Bentzen et al, 2010).

The mechanism leading to radiotherapy-induced late side effects is multifactorial. Irradiation may induce direct cell killing through DNA double-strand breaks. However, the interaction of ionising

*Correspondence: Dr H Lind; E-mail: helena.lind@ki.se

Received 28 March 201।; revised I July 201 I; accepted I9 July 20II; published online 16 August 2011 radiation with normal tissue also induces activation of cytokines and growth factors leading to a risk of fibrosis with decreased elasticity and compliance and increased risk of strictures. In addition, impaired function in blood- and lymph vessels along with neural damage may enhance the effect (Denham and Hauer-Jensen, 2002; Bentzen, 2006; Hauer-Jensen et al, 2007). Severe acute side effects have also been associated with consequential late effects in normal tissue (Dörr and Hendry, 2001). Together with patient characteristics, such as smoking, co-morbidities and genetic factors, these radiation-induced effects may lead to changes affecting specific physiological functions (Andreyev, 2007; Bentzen et al, 2010).

Radiation oncologists have a long tradition of recording late toxicity after cancer treatment. Several instruments exist, for example, the Franco-Italian glossary (Sinistrero et al, 1993), the RTOG/EORTC late radiation morbidity scoring schema (Rubin et al, 1995), the SOMA-LENT system (Mornex et al, 1997) and CTCAE (Trotti et al, 2003), but many of these combine multiple 
signs and symptoms into a single grade leading to loss of specificity. Only rarely have the toxicity scales been developed with guidance from the survivors. In addition, the great variety of study designs and measures of quality of life used in studies of gynaecological cancer survivors may make comparisons difficult. Although many of the questionnaires commonly used in clinical trials have been validated, for example, the FACT (Cella et al, 1993) and EORTC QLQ (Sprangers et al, 1993) questionnaires, these do not explore the impact of each specific symptom on daily activities (Steineck et al, 2002).

Personal identity numbers and official population-based registers in Sweden covering all Swedish citizens offer exceptionally good conditions for studying cancer survivors without selectioninduced problems. We performed a population-based cohort study on gynaecological cancer survivors concerning late symptoms after pelvic radiation therapy. We used a validated study-specific questionnaire in order to cover specific physical symptoms, sexuality, psychological dimensions and their impact on social functioning since no standardised existing instruments measure all these aspects. Here, we present self-reported symptoms from irradiated normal tissues, that is, the anal sphincter, the bowel, the urinary tract, the pelvic bones, the lower abdomen, legs and symptoms related to sexuality among gynaecological cancer survivors and compare their occurrence with that of populationbased control women. In addition, we present a detailed description of the demographic and clinical characteristics and how therapy was delivered in order to provide a background for coming publications.

\section{MATERIALS AND METHODS}

\section{Study population}

A cohort of 1800 women treated with external pelvic radiation therapy alone or as part of combination therapy for a gynaecological malignancy was identified. The women were consecutively treated between February 1991 and December 2003 at Radiumhemmet, Karolinska University Hospital in Stockholm or at Jubileumskliniken, Sahlgrenska University Hospital in Gothenburg (Figure 1). At follow-up in January 2006, 789 survivors (Stockholm $n=595$ and Gothenburg $n=194$ ) met the eligibility criteria, that is, born 1927 or later, being able to read and understand Swedish, and having no recurrent disease. Eligible survivors received an introductory letter. Medical records were reviewed to confirm the cancer diagnosis, stage of disease and treatment techniques regarding surgery, radiation therapy and chemotherapy.

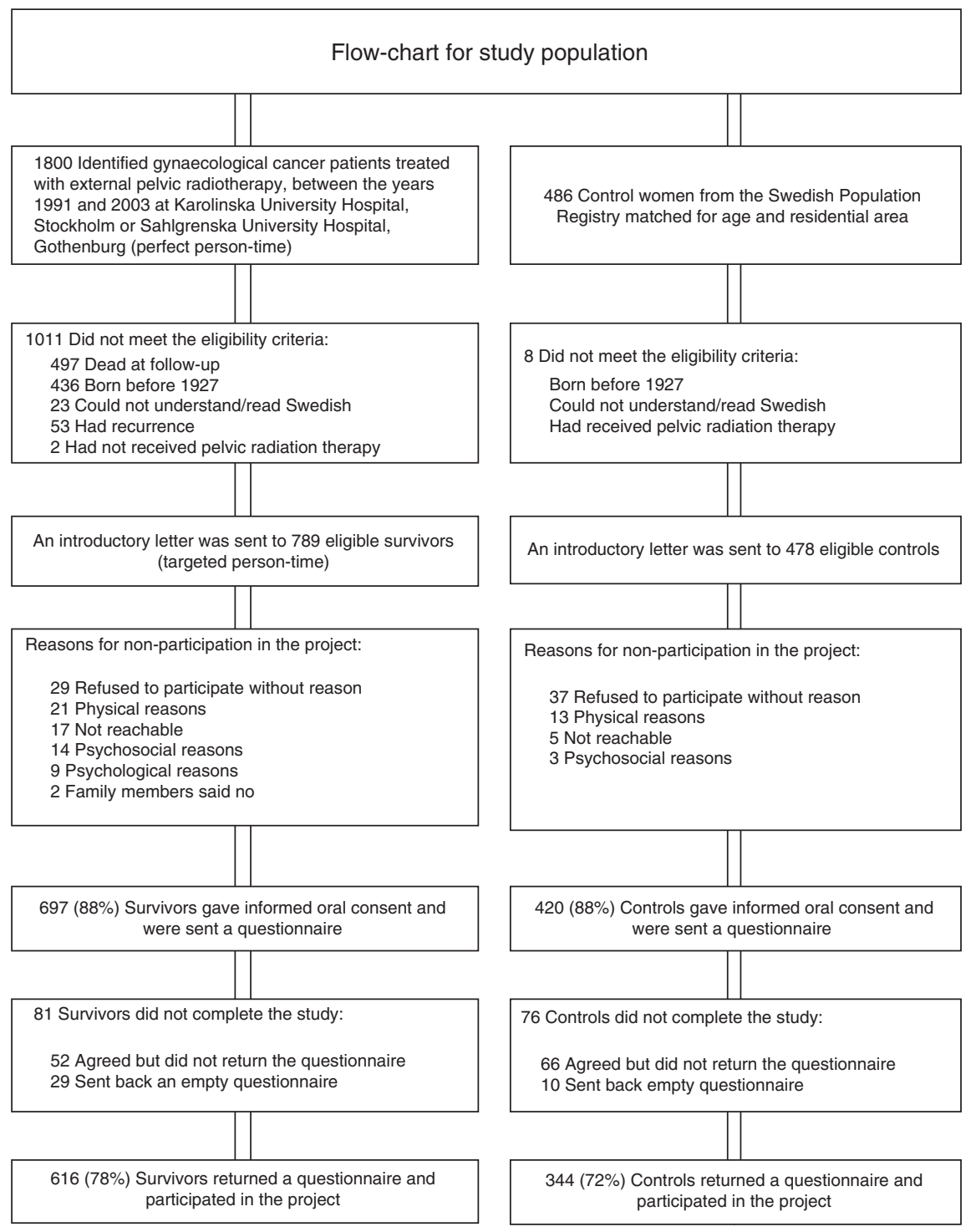

Figure I Flow chart for study population. 
As controls, we recruited 478 women from the Swedish Population Register, matched for age and residency and who had not had pelvic radiation therapy (Figure 1). An error in the matching procedure led to a younger control population (median age 57.5) compared with the cancer survivors (median age 66.0), which was adjusted for in the statistical analyses. The Regional Ethics Committee at the Karolinska Institute approved the study.

\section{Questionnaire}

Our methods for studies of cancer survivorship and development of study-specific questionnaires have been documented in $>80$ scientific papers (Bergmark et al, 1999; Steineck et al, 2006). A description of the development and validation of the present questionnaire has previously been reported (Dunberger et al, 2010). In summary, the questionnaire was developed during an 18 months long qualitative phase including semi-structured interviews with 26 gynaecological cancer survivors previously treated with pelvic radiation therapy. A study-specific questionnaire was constructed consisting of 351 questions covering symptoms from the gastrointestinal tract, urinary bladder, genitals, pelvic bones, abdomen and legs. Questions concerning demographics, sexual function, intercurrent diseases, psychological and quality-of-life issues were included. In each part of the questionnaire, we asked about the incidence, prevalence, intensity and duration of the symptoms and their impact on different aspects of social functioning.

Face-to-face validation of the final version was made to ensure that it was conceivable and had satisfactory internal consistency. Participation rate and rate of missing values were tested in a pilot study. The main study, the quantitative phase, was carried out during January-October 2006. Eligible women who gave informed consent received a postal questionnaire. Confidentiality was maintained by numbering the questionnaires.

\section{Radiation therapy}

Treatment was administered according to local treatment programmes and applied study protocols that were ongoing at the time of treatment. External beam radiation therapy (EBRT) was based on computed tomography (CT) scans performed before radiation therapy. Computed tomography scans were made in treatment position on a flat table top, using laser markers and conversion factors to electron density. Computed tomography slices ranged from 5 to $20 \mathrm{~mm}$. The EBRT dose was prescribed either at isocenter or as mean dose to the target covering at least $95 \%$ of the planning target volume (ICRU, 1993). Patients were treated in supine position, using linear accelerators or a racetrack accelerator with two opposing fields or a four-field box technique. Daily dose per fraction varied between 1.6 and $2.0 \mathrm{~Gy}$. External beam radiation therapy was verified by portal image films and with check-and-confirm systems. Brachytherapy (BT) was applied using standardised techniques and applicator templates. The BT dose was prescribed according to local practice. Pre-treatment orthogonal X-ray images verified the position of the BT applicator.

A detailed description of treatment techniques in relation to cancer diagnosis is provided in the Supplementary Appendix Table A1. For radiograph figures of typical treatment; see the Supplementary Appendix Figures A1-A4.

\section{Statistical analyses}

The results from the questionnaire and the data from the medical records were coded and transferred to the freeware data-entry program Epi-Data (http://www.epidata.dk). We used Fisher's exact test (Monte Carlo approximation, $10^{7}$ samples) to test for differences in survivors and control characteristics (Table 1). The test was two-sided and at the $5 \%$ significance level.
Different cut-off levels were used to describe the frequency of symptom occurrence. For initial analyses, a symptom was dichotomised into having the symptom occasionally or more often and into not having the symptom at all the past 6 months. In the final analyses, the cut-off level was changed into at least once a week in symptoms that had a high prevalence, that is, exceeding $45 \%$ in controls. We calculated the proportions having each outcome (symptom) among cancer survivors and control women, and used relative risk (RR) defined as the ratio between these proportions as outcome measure. Age-adjusted RRs with $95 \%$ confidence intervals (CIs) were calculated according to the logbinomial model (McNutt et al, 2003) including age as a categorical covariate with the categorisation used in Table 1 . Individuals with missing data were excluded from the calculations of each respective outcome. All calculations were performed using the SAS statistical software package (version 9.2, SAS Institute Inc., Cary, NC, USA).

\section{RESULTS}

In all, 616 of $789(78 \%)$ cancer survivors and 344 of $478(72 \%)$ control women returned a completed questionnaire and participated in the study (Figure 1). Median follow-up time was 74 months with a range of 26-179 months.

The median age for cancer survivors was 66.0 years and for control women 57.5 years (Table 1). Cancer survivors were more often single, had a lower level of education, lower degree of physical activity and were more often on disability pension compared with control women.

Nulliparity was twice as common among the survivors. Operational procedures at delivery and vaginal or perineal injury were less common among cancer survivors. The most common co-morbidity among cancer survivors was hypertension occurring in $38 \%$, compared with $27 \%$ in control women. Diabetes mellitus and heart failure were also more prevalent among cancer survivors. Endometrial cancer and cervical cancer were the most common diagnoses. In all, $84 \%$ of the cancer survivors were treated for stage I-II disease.

Overall $90 \%$ of the gynaecological cancer survivors were treated with surgery and EBRT with or without BT and chemotherapy. The remaining $10 \%$ consisted of a subset of cervical and vaginal cancer patients treated with radiation therapy alone (Figure 2). Additional information on demographic and clinical characteristics as well as a detailed description of treatment in relation to cancer diagnosis is provided in the Supplementary Appendix Table A1 and Supplementary Appendix Table A2. Treatment schedules for ovarian and fallopian tube cancer were identical and the results are hence presented together.

\section{Symptoms associated with cancer therapy}

With a median follow-up time of 6.2 years, cancer survivors reported a higher occurrence of symptoms from the anal sphincter, the bowel, the urinary tract, symptoms related to sexuality, the pelvic bones and the lower abdomen and legs, compared with control women (Table 2 and Supplementary Appendix A3).

The highest age-adjusted RR among anal-sphincter symptoms was for 'emptying of all stools into clothing without forewarning', RR 12.7 (95\% CI 4.0-40.3) with a prevalence of $12 \%$ among survivors and $0.9 \%$ among control women. This symptom was reported by one-third of the survivors with uterine sarcoma compared with $9 \%$ among survivors with endometrial and ovarian cancer. The prevalence of symptoms in relation to diagnosis is provided in the Supplementary Appendix Table A4. The occurrence of symptoms from the anal sphincter and bowel was in general higher among survivors with uterine sarcoma, cervical and vaginal cancer compared with endometrial and ovarian cancer survivors. 
Table I Demographic characteristics for gynaecological cancer survivors and control women

\begin{tabular}{lrrr}
\hline & $\begin{array}{c}\text { Cancer } \\
\text { survivors, } \\
\mathbf{N}=\mathbf{6 1 6} \mathbf{( \% )}\end{array}$ & $\begin{array}{c}\text { Control } \\
\text { women, }\end{array}$ & \\
$\mathbf{N = 3 4 4}(\%)$ & $\boldsymbol{P}^{-v a l u e} \mathbf{a}^{\mathrm{a}}$ \\
\hline Age & & & $<0.001$ \\
$28-49$ & $64 / 616(10)$ & $102 / 342(30)$ & \\
$50-59$ & $102 / 616(17)$ & $80 / 342(23)$ & \\
$60-69$ & $233 / 616(38)$ & $78 / 342(23)$ & \\
$70-79$ & $217 / 616(35)$ & $82 / 342(24)$ & \\
Median age, years (range) & $66.0(28-79)$ & $57.5(36-79)$ &
\end{tabular}

\section{Marital status}

Married or living with a partner $344 / 613$ (56) 220/344 (64)

Has a partner but lives alone $\quad 37 / 613(6) \quad 22 / 344(6)$ Widow

Single

$84 / 613(14) \quad 37 / 344(11)$

0.009

ducation

Elementary school

Secondary school

College or university

$196 / 615(32)$

$236 / 615(38)$

$183 / 615(30)$

$65 / 344(19)$

\section{Employment \\ Student \\ Unemployed \\ Employed \\ Housewife, other \\ On sick leave \\ Disability pension \\ Retired}

Country of birth
Sweden

Place of residency

Rural district

Village/town

$>500000$ citizen

$69 / 342(20)$

146/342 (43)

$127 / 342(37)$

$<0.00$ ।

moking

Current smoker

Former smoker

Never smoker

$B M P^{\mathrm{D}}$

$<18.5$ (underweight)

18.5-25.0 (normal weight)

25.0-30.0 (overweight)

$>30.0$ (obese)

$\mathrm{BMI}$, median (range)

Exercise

Never

Occasionally - at least

once a month

At least once a week

Parity

Nulli (never given birth)

1-3 para

$>3$ para

Delivery

Fast $<5 \mathrm{~h}$

Slow $>24 h$

Vacuum

Forceps

Episiotomy

Caesarean

Breech birth

$5 / 613(<1)$
$12 / 613(2)$
$202 / 613(33)$
$11 / 613(2)$
$11 / 613(2)$
$53 / 613(9)$
$319 / 613(52)$

$2 / 343(<1)$
$6 / 343(2)$
$188 / 343(55)$
$5 / 343(1)$
$10 / 343(3)$
$15 / 343(4)$
$117 / 343(34)$

$316 / 344(92) \quad<0.001$

0.402

$52 / 615(10) \quad 34 / 341(10)$

$191 / 615(31) \quad 93 / 34 \mid(27)$

$372 / 615$ (60) 214/34I (63)

144/607 (24) 88/343(26)

280/607 (46) 147/343(43)

16/575 (3) 5/327 (2)

$261 / 575(45) \quad 163 / 327(50)$

201/575 (35) 116/327(35)

$97 / 575(17) \quad 43 / 327(13)$

$25.1(16.0-53.1) 24.7(13.4-44.5)$

$76 / 599$ (13) 20/341 (6)

$78 / 599$ (13) 59/341 (17)

$154 / 615(25) \quad 45 / 344(13)$

$410 / 615(67) \quad 280 / 344(81)$

$51 / 615(8) \quad 19 / 344(6)$

$141 / 607(23)$

$41 / 607(7)$

12/607 (2)

132/607 (22)

28/607 (5)

18/607 (3)

0.608

0.256
183/607(30) 108/343(31)

445/599 (74) 262/34I (77)

250/607 (41) 147/342 (43)
Table I (Continued)

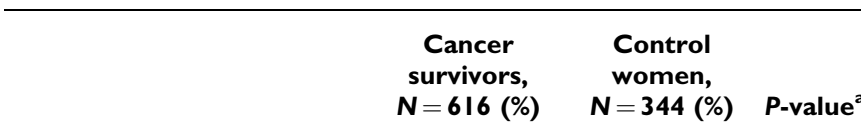

Delivery with birth weight $>4 \mathrm{~kg}$
$\quad \geq 2$

$\begin{array}{ll}78 / 612(13) & 54 / 344(16) \\ 42 / 612(7) & 29 / 344(8)\end{array}$

0.266

Pelvic floor injury

Vaginal or perineal injury

Anal sphincter injury

$\begin{array}{lcr}111 / 599(19) & 101 / 342(30) & <0.001 \\ 18 / 593(3) & 18 / 342(5) & 0.111\end{array}$

Intercurrent diseases

Previous abdominal surgery

Diabetes mellitus

Angina pectoris

Cardiac infarction

Heart failure

Hypertension

Crohn's disease, treatment for

Ulcerative colitis, treatment for

Irritable bowel syndrome,

treatment for

Haemorrhoids, treatment for

Lactose intolerance

Gluten intolerance

Pelvic organ prolapse,

treatment for

Rheumatism

Kidney disease

Lung disease

Thrombosis

Osteoporosis

Psychological disorders

Neurological disorders ${ }^{c}$

Medication

Using any kind of medication

$264 / 616(43)$
$58 / 611(9)$
$32 / 600(5)$
$18 / 600(3)$
$33 / 600(6)$
$227 / 600(38)$
$1 / 594(<1)$
$5 / 581(<1)$
$27 / 594(4)$

$156 / 344(45)$

0.456

$17 / 338(5)$

||$/ 34 \mid(3)$

0.016

$5 / 34 \mid(1)$

$8 / 341(2)$

$91 / 341(27)$

$0 / 332(0)$

$7 / 327(2)$

13/332 (4)

0.147

0.188

0.029

$<0.001$

$6|/ 59|(10) \quad 45 / 322(14) \quad 0.105$

$33 / 598(6)$

$8 / 604(1)$

$12 / 596(2)$

$|3 / 33|(4)$

0.334

$3 / 330(<1)-0.755$

13/332 (4) $\quad 0.094$

$37 / 600(6)$

$19 / 600(3)$

$19 / 34 \mid(6)$

$8 / 341(2)$

0.775

$40 / 600(7)$

$47 / 600(8)$

$|2 / 34|(4)$

$|6 / 34|(5)$

$25 / 34 \mid(7)$

$58 / 600(10)$

$78 / 600(13)$

$43 / 341(13)$

$3 / 341(<1)$

0.546

0.053

0.077

0.235

$15 / 600(3)$

0.919

0.089 $439 / 606(72)$
$224 / 606(37)$
$194 / 338(57)$

$50 / 339(15)<0.001$
Abbreviation: $\mathrm{BMI}=$ body mass index. Denominator is dependent on number of respondents answering a specific item and may differ from the maximum sum. Percentage may not total hundred because of rounding. ' $P$-value according to Fisher's exact test. ${ }^{b}$ Current BMI at the time the questionnaire was completed. 'Parkinson's disease, multiple sclerosis and epilepsy.

The highest age-adjusted RRs among urinary tract symptoms were observed for 'difficulty feeling the need to empty the bladder' (RR 2.8; 95\% CI 1.5-5.4) with a prevalence of $9 \%$ in survivors compared with $3 \%$ in control women. The corresponding figures for 'difficulty feeling a full bladder' (RR 2.7; 95\% CI 1.6-4.5), was $15 \%$ in cancer survivors compared with $5 \%$ in control women. These symptoms occurred more frequently among survivors treated with radiation therapy alone compared with those treated with surgery and radiation therapy.

For symptoms related to sexuality, $34 \%$ of the survivors reported 'absence of vaginal elasticity' compared with $14 \%$ among control women (RR 1.8; 95\% CI 1.3-2.4). This symptom occurred in $47 \%$ of survivors treated with radiation therapy alone. 'Deep dyspareunia when having intercourse' occurred in $17 \%$ of cancer survivors irrespective of treatment modality, compared with 7\% among control women (RR 3.7; 95\% CI 2.4-5.7). About one-third of the survivors reported a 'decreased ability for intercourse leading to a lower intercourse frequency'.

Pubic bone pain was at least three times as common among survivors compared with control women. The highest age-adjusted RR was for 'pubic pain when walking indoors', RR 4.9 (95\% CI 2.1-11.6). Among survivors treated with radiation therapy alone, this symptom was reported by $18 \%$ compared with $2 \%$ among control women (RR 10.3; 95\% CI 4.0-26.7). 


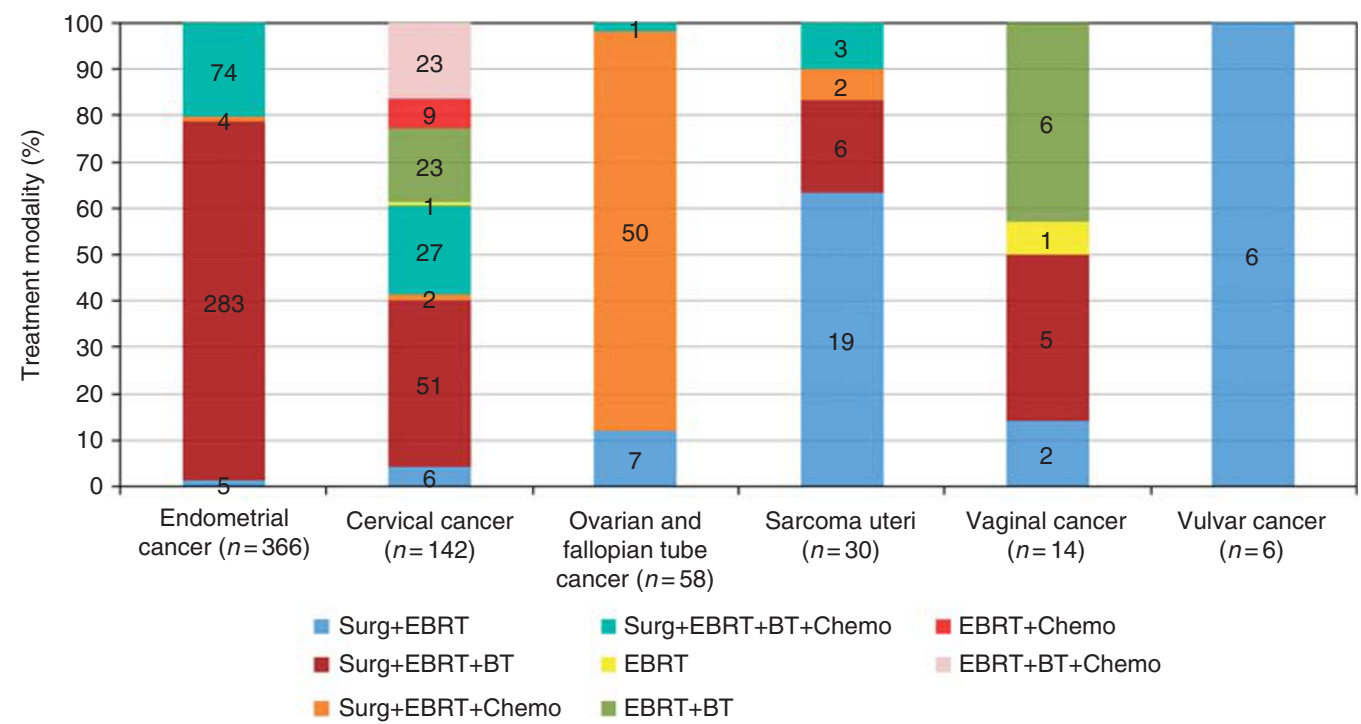

Figure 2 Treatment modality dependent on diagnosis. Abbreviations: Surg=surgery; EBRT=external beam radiation therapy; BT= brachytherapy; chemo $=$ chemotherapy.

For the abdomen and legs the highest age-adjusted RR was for 'erysipelas on abdomen or legs', RR 3.6 (95\% CI 1.0 - 12.8) followed by 'lower abdominal heaviness', RR 2.1 (95\% CI 1.5-3.0) occurring in one-fifth of the survivors. The prevalence among survivors treated with radiation therapy alone was $30 \%$, compared with $11 \%$ among control women.

\section{DISCUSSION}

Gynaecological cancer survivors treated with pelvic radiation therapy alone or as part of combined treatment reported higher occurrence of late specific symptoms from all normal tissues addressed in the study, that is, the anal sphincter, the bowel, the urinary tract, the pelvic bones, the lower abdomen and legs as well as symptoms related to sexuality compared with matched control women.

Although gastrointestinal side-effects following pelvic radiation therapy are well documented, the occurrence and specificity of anal sphincter and bowel symptoms in long-term survivors have been less well studied (Andreyev, 2005; Putta and Andreyev, 2005). We have in a previous publication reported on our findings of higher occurrence of gastrointestinal symptoms and a 12-fold higher occurrence of emptying of all stools into clothing without forewarning among long-term gynaecological cancer survivors compared with controls. This severe faecal incontinence symptom was more prevalent in survivors treated for cervical cancer and uterine sarcoma. These diagnoses had in general higher median EBRT doses. In a previous study from our group, 65 prostate cancer survivors were asked by means of a study-specific postal questionnaire about bowel and urinary symptoms and sexual function 2-4 years after curative EBRT to the prostate. A correlation was found between the dose to the anal sphincter and faecal leakage in the interval of $45-55 \mathrm{~Gy}$ and also a correlation between defaecation urgency and loose stools and the dose to the rectum in the interval of $25-42 \mathrm{~Gy}$ (al-Abany et al, 2005). It is reasonable to also investigate the impact of dose to bowel and anal sphincter in relation to the occurrence of emptying of all stools without forewarning.

The urinary bladder has been regarded as less radiosensitive compared with the bowel (Marks et al, 1995). Late urinary sideeffects appear to be less common but there are few published reports on the prevalence of specific urinary symptoms among long-term gynaecological cancer survivors. With median follow-up of 60 and 68 months, the PORTEC- 1 trial reported a prevalence of $8 \%$ of mild genitourinary complications (measured by FrenchItalian glossary), while the GOG99 trial reported a $25 \%$ genitourinary complication rate (assessed by the 1985 GOG Adverse Events Criteria scale) after postoperative EBRT in women with early stages of endometrial cancer (Creutzberg et al, 2001; Keys et al, 2004). In the PORTEC-1 trial, the complications consisted of urinary urgency, recurrent urinary infections and minor incontinence while no details on specific symptoms are specified in the GOG 99 trial report. A higher risk of late urinary side-effects is reported for cervical cancer, which may be related to the higher doses of radiation therapy used (Elliott and Malaeb, 2011). In an observational study by Pieterse et al (2006), no increased occurrence of bladder dysfunction was reported at 24 months' follow-up in 94 early-stage cervical cancer patients treated with postoperative EBRT, compared with surgery alone or control women. Nearly, every study shows that late post-radiation urinary morbidity continues to progress decades after radiation therapy. The short follow-up period and the restriction to only two questions concerning micturition may have contributed to the results reported by Pieterse et al (2006). In a population-based survey of 291 cervical cancer survivors with an average follow-up period of 6.6 years, self-reported symptoms of frequent micturition were reported by 42 and $45 \%$ following radiation therapy alone or postoperative EBRT (Korfage et al, 2009). Urinary leakage was reported by 19 and $26 \%$ and difficulties emptying the bladder in $6 \%$ and $11 \%$, respectively. These results are in line with our findings. Besides difficulties emptying the bladder, urinary incontinence, urgency and cystitis, the survivors in our study also reported difficulties feeling a full bladder. Our results indicate that late side-effects from the urinary tract following radiation therapy are underestimated and underreported.

Most previous population-based surveys addressing the impact of radiation therapy on normal tissues have focused on sexuality in survivors after treatment of cervical cancer. In a population-based cohort study of long-term early stage cervical cancer, survivors reported more sexual dysfunction resulting in considerable distress, compared with control women (Bergmark et al, 1999). The impact of radiation therapy on sexual function has since then been confirmed in several publications (Jensen et al, 2003; Frumovitz et al, 2005; Park et al, 2007; Korfage et al, 2009). Some results support the positive effect of using vaginal dilators to 
Table 2 Late symptoms during the past 6 months among gynaecological cancer survivors treated with pelvic radiation therapy with or without surgery and control women

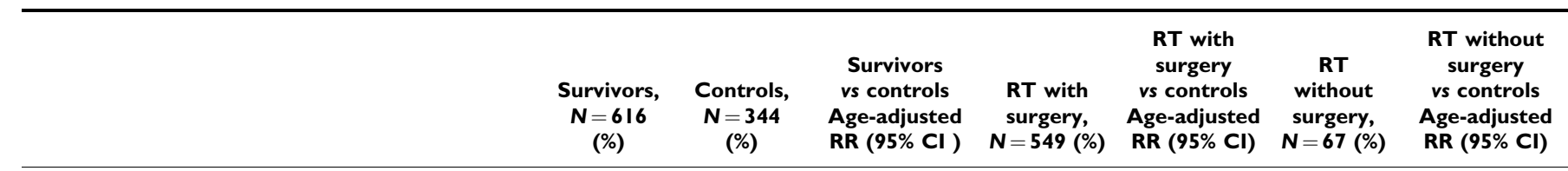

Anal-sphincter symptoms

Emptying of all stools into clothing without

forewarning at least occasionally

Leakage of loose stools while awake at least occasionally Leakage of loose stools while asleep at least occasionally

Anal leakage of mucus while asleep at least occasionally

Leakage of solid stools while awake at least occasionally

Faecal leakage without forewarning despite previous

defaecation at least occasionally

Defaecation urgency with faecal leakage at least

occasionally

Foul smelling flatulence at least once a week

Anal leakage of mucus while awake at least occasionally

Self-perception of faecal odour at least occasionally

Involuntary flatulence at least once a week

Unwanted defaecation while emptying bladder at least occasionally

Anal leakage of blood while awake at least occasionally

Involuntary loud flatulence at least occasionally

Bowel symptoms

Defaecation urgency at least once a week

Protracted abdominal pain lasting $>$ I year, yes

Loose stools at least once a week

Abdominal pain and vomiting at least occasionally

Mucus in stools at least occasionally

Abdominal bloating at least once a week

Rectal bleeding at least occasionally

Abdominal pain and stools at least occasionally

Abdominal pain at least occasionally

Abdominal pain and bloating at least occasionally

Urinary tract symptoms

Difficulty feeling the need to empty bladder at least

occasionally

Difficulty emptying bladder at least occasionally

Difficulty feeling full bladder at least occasionally

Haematuria at least occasionally

Straining to initiate emptying of bladder at least

occasionally

Painful emptying of bladder at least occasionally

Urinary incontinence without urinary urgency at

least occasionally

Night-time emptying of bladder at least twice per

night or more, yes

Need of antibiotics because of urinary tract infection

twice or more, yes

Urinary incontinence because of urinary urgency

at least occasionally

Slow emptying of bladder at least occasionally

Self-perception of urine odour at least occasionally

Urinary urgency at least occasionally

Feeling of incomplete bladder emptying at least occasionally

Symptoms related to sexuality

Protracted genital pain lasting for $>$ I year, yes

Genital bleeding during or after intercourse at

least once, yes

Deep dyspareunia when having intercourse,

at least a little

Vaginal lubrication when sexually aroused, no

Decreased ability for intercourse leading to lower

intercourse frequency, at least a little

Vaginal elasticity, no

Genital swelling when sexually aroused, no

Superficial dyspareunia when having intercourse,

at least a little

Sensitivity to touch inside vagina, no

Sensitivity to touch of labia and clitoris, no

\section{$70 / 606(12)$}

$199 / 608(33)$

$72 / 611(12)$

$32 / 607(5)$

$46 / 607$ (8)

| 88/605 (31)

298/603 (49)

3/344 (0.9)

$18 / 344(5)$

$8 / 343(2)$

$4 / 344(1)$

$5 / 344(1)$

23/344 (7)

1 16/602 (19)

22/343 (6)

$87 / 603$ (14) 14/343 (4)

$108 / 606(18) \quad 18 / 340(5)$

$127 / 606(21) \quad 33 / 343(10)$

238/603 (39) 57/342(17)

42/608 (7) 12/343 (4)

$359 / 607$ (59) $\quad 150 / 344(44)$

175/602 (29)

$69 / 593(12)$

234/602 (39)

$60 / 605(10)$

I56/607 (26)

147/605 (24)

$103 / 604(17)$

198/602 (33)

$307 / 604(51)$

228/603 (38)

19/34| (6)

$15 / 339$ (4) 48/344 (14) $13 / 344(4)$ $45 / 343$ (13) $60 / 342(18)$ $42 / 34 I(12)$ $79 / 343(23)$ $37 / 340(40)$

$56 / 604(9)$

| I/343 (3)

$49 / 602(8)$

$11 / 343(3)$

$90 / 602(15)$

20/606 (3)

$77 / 605$ (13)

$60 / 605$ (I0) 20/34|(6)

$88 / 603$ (15) 24/342 (7)

222/607 (37) 58/34I (17)

$93 / 605(15) \quad 31 / 344(9)$

209/607 (34) 66/342(19)

$122 / 605$ (20) 47/344(14) |49/605 (25) 62/34|(18) $346 / 605(57) \quad 139 / 343(41)$ 232/604 (38) $101 / 343(29)$
5.7 (3.5 - 9.1) $\quad \mid 57 / 542(29) \quad 5.7$ (3.5 - 9.I)

3.2 (1.9-5.6) $59 / 532(11) \quad 3.1$ (1.7-5.5)

3.0 (2.2-3.9) $205 / 540(38) \quad 2.9$ (2.1 -3.9)

2.6 (I.4-4.7) $\quad 49 / 545(9) \quad 2.2$ (I.2-4.I)

$2.1(\mathbf{1 . 5 - 3 . 0 )} \quad \mid 43 / 545(26) \quad 2.2(\mathbf{I . 6}-\mathbf{3 . 0})$

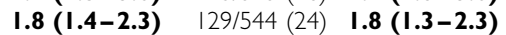

I.6 (I.I - 2.2) $92 / 545$ (I7) I.6 (I.2-2.4)

I.6 (I.3-2.0) $\quad|7| / 54 \mid(32) \quad \mathbf{I . 5}(\mathbf{I . 2}-\mathbf{I . 9})$

I.4 (I.2- I.6) 272/544(50) I.4 (I.2- I.6)

I.4 (I.2- I.7) $199 / 542(37) \quad$ I.4 (I.2- I.7)

$2.8(1.5-5.4)$

$2.7(1.4-5.2)$

$2.7(1.6-4.5)$

$2.5(0.9-6.9)$

$2.2(1.4-3.7)$

$2.0(1.2-3.3)$

$1.8(1.2-2.9)$

46/544 (8)

$2.5(1.3-5.0)$

$43 / 542(8) \quad 2.7(\mathbf{I} .4-5.5)$

$76 / 543$ (14) 2.4 (1.4-4.1)

$16 / 546$ (3) $2.4(0.8-6.8)$

$68 / 545$ (12) 2.4 (1.5-3.9)

$52 / 545(10) \quad 1.9(\mathbf{l} .1-3.3)$

$81 / 543$ (I5) $\quad$ I.9 (I.2-3.0)

$1.8(1.4-2.4)$

199/548 (36) I.8 (I.4-2.4)

$1.6(1.1-2.3)$

$86 / 545$ (I6) I.7 (I.I - 2.5)

$1.6(1.2-2.0)$

| 86/545 (34) I.5 (I.2-2.0)

$1.6(1.2-2.2)$

$1.4(1.1-1.9)$

$1.3(1.1-1.5)$

106/546 (19) 1.5 (I.I - 2.2)

I26/544 (23) I.3 (I.0- I.8)

308/544 (57) I.3 (I.I- I.5)

$1.3(1.1-1.6)$

$203 / 544$ (37) I.3 (I.0- I.6)

I5/60 (25) $30.3(9.1-101.1)$

28/63 (44)

$14 / 63(22)$

$7 / 62(11)$

$9 / 63(14)$

20/60 (33)

36/62 (58)

|4/6 | (23)

$11 / 61(18)$

$13 / 62(2 \mid)$

$16 / 6$ | (26)

25/62 (40)

$5 / 63$ (8)

45/61 (74)

$18 / 60(30)$

$10 / 61(16)$

$29 / 62(47)$

I I/60 (I8)

$13 / 62(21)$

$18 / 6 \mid(30)$

||$/ 59(19)$

$27 / 61$ (44)

$35 / 60(58)$

29/6। (48)

$8.5(5.0-14.5)$

$9.8(4.3-22.4)$

$9.7(2.9-32.3)$

$9.3(3.2-27.0)$

4.8 (2.8-8.2)

$4.8(3.3-6.8)$

$3.6(2.0-6.7)$

$4.1(1.9-8.6)$

$4.0(2.1-7.8)$

$2.8(1.7-4.8)$

$2.3(1.6-3.4)$

$2.2(0.8-6.7)$

I.7 (1.4-2.1)

$6.0(3.3-10.8)$

$3.8(1.8-7.9)$

$3.5(2.4-5.1)$

$4.8(2.2-10.1)$

$1.6(0.9-2.8)$

I.8 (I.I - 2.7)

$1.5(0.8-2.8)$

$2.0(1.4-2.8)$

$1.5(1.2-1.9)$

$1.6(1.2-2.1)$

10/60 (17)

$5.1(2.3-11.3)$

$6 / 60(10)$

$14 / 59$ (24)

$4 / 60(7)$

$9 / 60(15)$

$3.2(1.3-8.4)$

$4.5(2.4-8.4)$

$5.0(1.4-17.8)$

$2.5(1.2-5.3)$

$8 / 60(13) \quad 2.3(\mathbf{I}) \mathbf{- 1} \mathbf{5 . 0})$

$7 / 60(12) \quad 1.6(0.7-3.6)$

23/59 (39)

$2.2(1.5-3.2)$

$7 / 60(12)$

$1.3(0.6-2.9)$

23/62 (37)

$1.8(1.2-2.7)$

|6/59 (27)

$23 / 6 \mid(38)$

$38 / 6 \mid(62)$

$2.0(1.2-3.3)$

$2.1(1.4-3.0)$

$1.5(1.2-1.8)$

29/60 (48)

$1.6(1.2-2.2)$

\begin{tabular}{|c|c|c|c|c|c|c|}
\hline $\begin{array}{l}28 / 593(5) \\
54 / 585(9)\end{array}$ & $\begin{array}{r}4 / 339(1) \\
13 / 329(4)\end{array}$ & $\begin{array}{l}5.0(1.7-14.5) \\
3.7(2.1-6.7)\end{array}$ & $\begin{array}{l}21 / 532(4) \\
45 / 523(9)\end{array}$ & $\begin{array}{l}4.3(1.4-13.0) \\
3.6(2.0-6.7)\end{array}$ & $\begin{array}{l}7 / 61(11) \\
9 / 62(15)\end{array}$ & $\begin{array}{l}9.6(2.9-31.8) \\
3.9(1.8-8.4)\end{array}$ \\
\hline $101 / 583(17)$ & 23/330 (7) & $3.7(2.4-5.7)$ & $90 / 521(17)$ & $3.7(2.4-5.8)$ & 11/62 (18) & $3.0(1.6-5.7)$ \\
\hline $\begin{array}{c}39 / 577(7) \\
\mid 76 / 575(3 \mid)\end{array}$ & $\begin{array}{c}7 / 333(2) \\
37 / 327(11)\end{array}$ & $\begin{array}{l}2.9(1.3-6.4) \\
2.9(2.1-4.1)\end{array}$ & $\begin{array}{c}37 / 5 \mid 7(7) \\
160 / 5 \mid 5(3 \mid)\end{array}$ & $\begin{array}{l}2.9(1.3-6.5) \\
2.9(2.0-4.0)\end{array}$ & $\begin{array}{c}2 / 60(3) \\
11 / 60(18)\end{array}$ & $\begin{array}{c}1.6(0.3-7.5) \\
\mathbf{2 . 5}(\mathbf{I . 5}-\mathbf{4 . 1})\end{array}$ \\
\hline $\begin{array}{r}\mid 72 / 502(34) \\
82 / 57 \mid(14) \\
\mid 40 / 584(24)\end{array}$ & $\begin{array}{l}41 / 302(14) \\
35 / 327(11) \\
67 / 330(20)\end{array}$ & $\begin{array}{l}1.8(1.3-2.4) \\
1.5(1.0-2.2) \\
I .5(1.2-2.0)\end{array}$ & $\begin{array}{r}|48 / 45| \\
72 / 5 \mid 2(14) \\
\mid 25 / 523(24)\end{array}$ & $\begin{array}{l}\text { I.6 (I.2-2.2) } \\
1.5(1.0-2.2) \\
\text { I.5 (I.I-2.0) }\end{array}$ & $\begin{array}{l}24 / 5 \mid(47) \\
10 / 59(17) \\
|5 / 6|(25)\end{array}$ & $\begin{array}{c}2.5(\mathbf{I . 7}-\mathbf{3 . 7}) \\
1.6(0.9-3.1) \\
1.4(0.8-2.2)\end{array}$ \\
\hline $\begin{array}{l}22 \mid / 540(4 \mid) \\
\mid 86 / 558(33)\end{array}$ & $\begin{array}{l}65 / 310(21) \\
61 / 320(19)\end{array}$ & $\begin{array}{l}\text { I.3 (I.0- I.6) } \\
1.2(0.9-1.5)\end{array}$ & $\begin{array}{l}\mid 92 / 485(40) \\
|63 / 50|(33)\end{array}$ & $\begin{array}{l}1.2(1.0-1.5) \\
1.1(0.9-1.4)\end{array}$ & $\begin{array}{l}29 / 55(53) \\
23 / 57(40)\end{array}$ & $\begin{array}{l}1.7(1.3-2.2) \\
1.5(1.1-2.1)\end{array}$ \\
\hline
\end{tabular}

British Journal of Cancer (20II) I 05(6), 737-745

(c) 201 I Cancer Research UK 


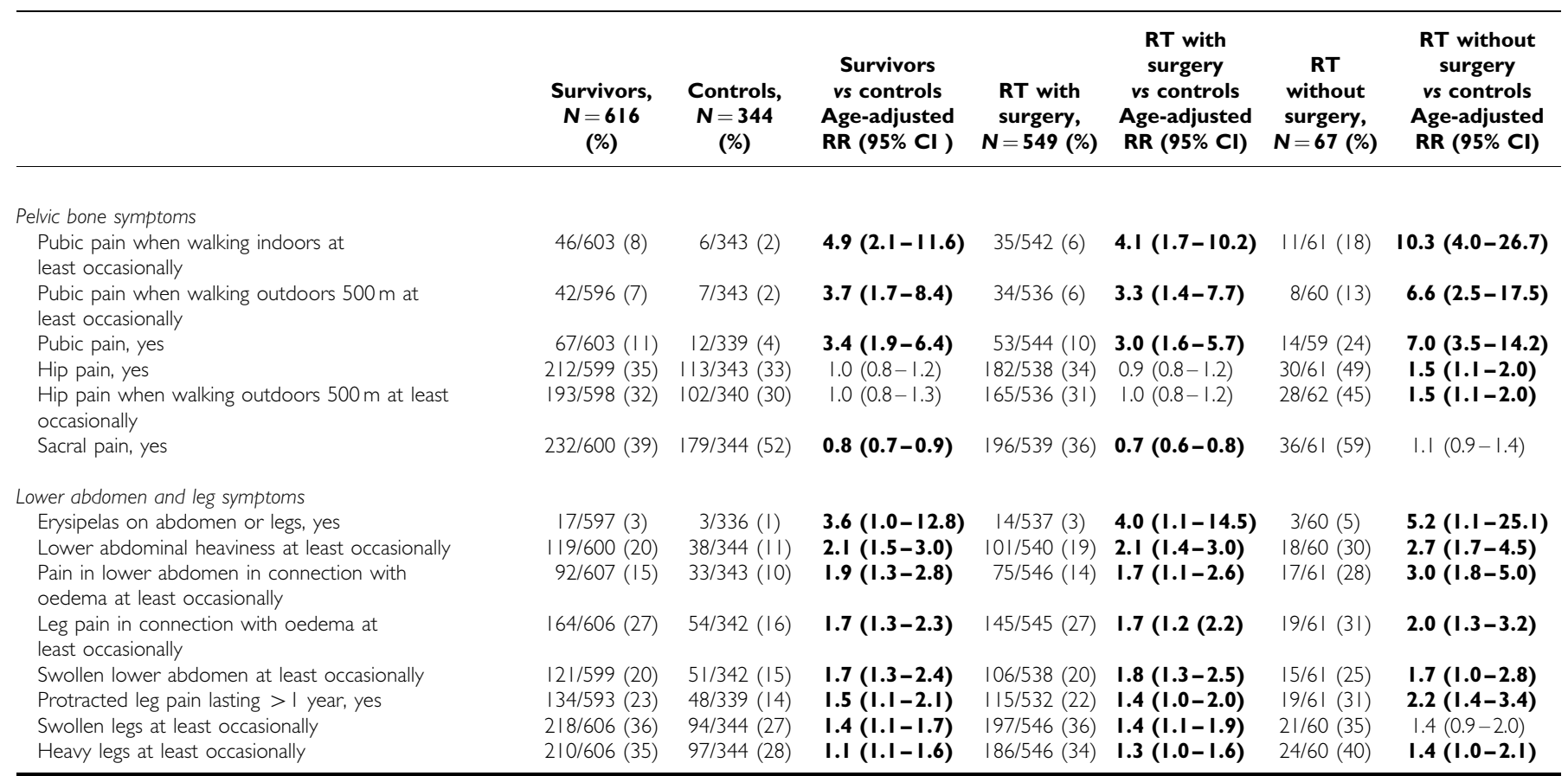

Abbreviations: $\mathrm{Cl}=$ confidence interval; $\mathrm{RR}=$ relative risk; $\mathrm{RT}=$ radiation therapy. Bold entries indicate statistic significance. The symptoms are sorted into anatomical region of supposed origin and in size order for RR, the number in the denominator may vary because of missing information.

prevent development of vaginal stenosis following radiation therapy as reviewed by the Cochrane Collaboration (Denton and Maher, 2003).

We have in a previous publication reported on the findings of higher occurrence of pubic bone symptoms and increased frequency of pubic bone pain with mean absorbed dose exceeding $52.5 \mathrm{~Gy}$ to the pubic bone (Waldenström et al, 2010). Cancer survivors in our study treated with radiation therapy alone also reported a higher prevalence of hip pain. The potential relationship between hip pain and radiation dose will be addressed in a coming report from our group.

Lymph oedema is a common late symptom among gynaecological cancer survivors (Bergmark et al, 2006). In a populationbased mailed survey of 802 gynaecological cancer survivors (Beesley et al, 2007), 25\% were diagnosed with lymph oedema or had symptomatic lower limb swelling. A higher prevalence was observed in vulvar cancer survivors. These results are consistent with our findings. The survivors in our study also report a higher occurrence of heaviness or swollen lower abdomen. The prevalence was higher after radiation therapy alone than after combination of surgery and radiation therapy. One may speculate that fibrosis or occlusion of lymph vessels after radiation therapy may be involved in the mechanism behind this symptom.

Some of the strengths of this study are the large populationbased patient cohort and the high participation rate. Access to all medical records has ensured correct information regarding clinical characteristics and detailed knowledge of administered treatment. The construction of the study-specific questionnaire in close cooperation with the gynaecological cancer survivors, comprehensive face-to-face validation and the use of a privately answered questionnaire lowered the risk for measurement errors and eliminated interviewer-induced bias. By asking for symptom occurrence during the past 6 months, we avoided capturing temporary symptoms produced by chance and at the same time minimised risk of recall-induced problems. Symptoms were atomised, subdivided into very specific questions, which may have contributed to survivors' multitude of symptoms. In an effort to increase participation, we did not include subjects over the age of 80 years. We cannot, however, exclude the possibility that nonparticipating subjects would have answered differently. The loss of information from part of the targeted-person-time may result in a deviation between the true effect measure and the observed effect measure in a way that is unpredictable. The minimum internal response rate for individual questions was $81 \%$ (502 out of 616) for survivors and $88 \%$ (302 out of 344 ) for control women in questions dealing with sexuality. This may negatively affect the generalisability of the study result. Individuals who failed to respond to a certain question were excluded from the analysis of that outcome. In all tables, the response rates can be assessed through the denominator that is presented for all items.

Research regarding long-term treatment effects in cancer survivors will give us knowledge for developing new strategies in cancer treatment. Updated recommendations are gradually introduced into clinical use. Several randomised clinical trials investigating the outcome of adjuvant radiation therapy in endometrial cancer patients have shown an increased risk of late radiation therapy-induced morbidity but without survival benefit (Creutzberg et al, 2001; Keys et al, 2004; Nout et al, 2009). Hence, adjuvant radiation therapy is nowadays seldom given to endometrial patients with low-intermediate risk malignancy. A potential new treatment approach is TGF- $\beta$, which is a promising target for preventing radiotherapy-induced fibrosis (Anscher, 2010). In addition, we also believe that prevention of some symptoms may be achieved by optimising radiation delivery by improved target imaging and treatment planning with doseconstraints guidelines and by the use of intensity modulated radiation therapy (Small et al, 2008).

In this first stage of our gynaecological cancer survivorship programme, we report on the occurrence of symptoms from normal tissues after pelvic irradiation. In the second stage of our programme, we will continue the reporting of the impact of specific symptoms on daily life activities and quality of life. The 
study cohort is highly heterogeneous and these circumstances contribute to variability of the absorbed dose of ionising radiation to the normal tissue surrounding the target, which will enable us to study the dose-volume effects of radiation therapy to normaltissues in relation to self-reported symptoms. In the third stage of our survivorship programme, we intend to explore which levels of ionising radiation delivered to specific volumes of normal tissue surrounding the target that contribute to the occurrence of a specific symptom, which can affect quality of life. This may help the radiotherapist to optimise dose planning and thereby hopefully reduce the symptom burden among future long-term gynaecological cancer survivors.

\section{ACKNOWLEDGEMENTS}

We would like to thank all women who participated in the study. We would also like to thank Dr Lawrence Lundgren for skilful linguistic revision. This study was funded by grants from the Swedish Cancer Society, the Cancer Research Funds of Radiumhemmet, the King Gustav V Jubilee Clinic Cancer Foundation, Gothenburg and the Swedish State under the ALF agreement, Stockholm and Gothenburg.

Supplementary Information accompanies the paper on British Journal of Cancer website (http://www.nature.com/bjc)

\section{REFERENCES}

al-Abany M, Helgason AR, Cronqvist AK, Lind B, Mavroidis P, Wersäll P, Lind H, Qvanta E, Steineck G (2005) Toward a definition of a threshold for harmless doses to the anal-sphincter region and the rectum. Int $J$ Radiat Oncol Biol Phys 61: 1035-1044

Andreyev HJ (2007) Gastrointestinal problems after pelvic radiotherapy: the past, the present and the future. Clin Oncol (R Coll Radiol) 19: 790 - 799

Andreyev J (2005) Gastrointestinal complications of pelvic radiotherapy: are they of any importance? Gut 54: $1051-1054$

Anscher MS (2010) Targeting the TGF-betal pathway to prevent normal tissue injury after cancer therapy. Oncologist 15: 350-359

Beesley V, Janda M, Eakin E, Obermair A, Battistutta D (2007) Lymphedema after gynecological cancer treatment: prevalence, correlates, and supportive care needs. Cancer 109: 2607-2614

Bentzen SM (2006) Preventing or reducing late side effects of radiation therapy: radiobiology meets molecular pathology. Nat Rev Cancer 6: $702-713$

Bentzen SM, Constine LS, Deasy JO, Eisbruch A, Jackson A, Marks LB, Ten Haken RK, Yorke ED (2010) Quantitative analyses of normal tissue effects in the clinic (QUANTEC): an introduction to the scientific issues. Int J Radiat Oncol Biol Phys 76: S3-S9

Bergmark K, vall-Lundqvist E, Dickman PW, Henningsohn L, Steineck G (1999) Vaginal changes and sexuality in women with a history of cervical cancer. $N$ Engl J Med 340: $1383-1389$

Bergmark K, vall-Lundqvist E, Dickman PW, Henningsohn L, Steineck G (2006) Lymphedema and bladder-emptying difficulties after radical hysterectomy for early cervical cancer and among population controls. Int J Gynecol Cancer 16: $1130-1139$

Cella DF, Tulsky DS, Gray G, Sarafian B, Linn E, Bonomi A, Silberman M, Yellen SB, Winicour P, Brannon J, Eckberg K, Lloyd S, Purl S, Blendowdki C, Goodman M, Barnicle M, Stewart I, Mchale M, Bonomi P, Kaplan E, Taylor S, Thomas CR, Harris J (1993) The functional assessment of cancer therapy scale: development and validation of the general measure. J Clin Oncol 11: $570-579$

Creutzberg CL, van Putten WL, Koper PC, Lybeert ML, Jobsen JJ, Warlam-Rodenhuis CC, De Winter KA, Lutgens LC, van den Bergh AC, van der Steen-Banasik E, Beerman H, van Lent M (2001) The morbidity of treatment for patients with stage I endometrial cancer: results from a randomized trial. Int J Radiat Oncol Biol Phys 51: $1246-1255$

Denham JW, Hauer-Jensen M (2002) The radiotherapeutic injury-a complex 'wound'. Radiother Oncol 63: 129-145

Denton AS, Maher EJ (2003) Interventions for the physical aspects of sexual dysfunction in women following pelvic radiotherapy. Cochrane Database Syst Rev (1): CD003750 Art. no.

Dörr W, Hendry JH (2001) Consequential late effects in normal tissues. Radiother Oncol 61: 223-231

Dunberger G, Lind H, Steineck G, Waldenström AC, Nyberg T, Al-Abany M, Nyberg U, Åvall-Lundqvist E (2010) Self-reported symptoms of faecal incontinence among long-term gynaecological cancer survivors and population-based controls. Eur J Cancer 46: 606-616

Eifel PJ, Levenback C, Wharton JT, Oswald MJ (1995) Time course and incidence of late complications in patients treated with radiation therapy for FIGO stage IB carcinoma of the uterine cervix. Int J Radiat Oncol Biol Phys 32: $1289-1300$

Elliott SP, Malaeb BS (2011) Long-term urinary adverse effects of pelvic radiotherapy. World J Urol 29: 35-41
Frumovitz M, Sun CC, Schover LR, Munsell MF, Jhingran A, Wharton JT, Eifel P, Bevers TB, Levenback CF, Gershenson DM, Bodurka DC (2005) Quality of life and sexual functioning in cervical cancer survivors. J Clin Oncol 23: $7428-7436$

Grigsby PW, Russell A, Bruner D, Eifel P, Koh WJ, Spanos W, Stetz J, Stitt JA, Sullivan J (1995) Late injury of cancer therapy on the female reproductive tract. Int J Radiat Oncol Biol Phys 31: 1281-1299

Hauer-Jensen M, Wang J, Boerma M, Fu Q, Denham JW (2007) Radiation damage to the gastrointestinal tract: mechanisms, diagnosis, and management. Curr Opin Support Palliat Care 1: 23-29

International Commission on Radiation Units and Measurements (1993) Prescribing, recording and reporting photon beam therapy. ICRU Report 50

Jensen PT, Groenvold M, Klee MC, Thranov I, Petersen MA, Machin D (2003) Longitudinal study of sexual function and vaginal changes after radiotherapy for cervical cancer. Int J Radiat Oncol Biol Phys 56: 937-949

Keys HM, Roberts JA, Brunetto VL, Zaino RJ, Spirtos NM, Bloss JD, Pearlman A, Maiman MA, Bell JG (2004) A phase III trial of surgery with or without adjunctive external pelvic radiation therapy in intermediate risk endometrial adenocarcinoma: a Gynecologic Oncology Group study. Gynecol Oncol 92: 744-751

Korfage IJ, Essink-Bot ML, Mols F, van de Poll-Franse L, Kruitwagen R, van Ballegooijen M (2009) Health-related quality of life in cervical cancer survivors: a population-based survey. Int J Radiat Oncol Biol Phys 73: $1501-1509$

Marks LB, Carroll PR, Dugan TC, Anscher MS (1995) The response of the urinary bladder, urethra, and ureter to radiation and chemotherapy. Int J Radiat Oncol Biol Phys 31: 1257-1280

McNutt LA, Wu C, Xue X, Hafner JP (2003) Estimating the relative risk in cohort studies and clinical trials of common outcomes. Am J Epidemiol 157: $940-943$

Mornex F, Pavy JJ, Denekamp J, Bolla M (1997) [Scoring system of late effects of radiations on normal tissues: the SOMA-LENT scale]. Cancer Radiother 1: $622-668$

Nout RA, Putter H, Jurgenliemk-Schulz IM, Jobsen JJ, Lutgens LC, van der Steen-Banasik EM, Mens JW, Slot A, Stenfert Kroese MC, van Bunningen BN, Smit VT, Nijman HW, van den Tol PP, Creutzberg CL (2009) Quality of life after pelvic radiotherapy or vaginal brachytherapy for endometrial cancer: first results of the randomized PORTEC-2 trial. J Clin Oncol 27: $3547-3556$

Park SY, Bae DS, Nam JH, Park CT, Cho CH, Lee JM, Lee MK, Kim SH, Park SM, Yun YH (2007) Quality of life and sexual problems in diseasefree survivors of cervical cancer compared with the general population. Cancer 110: 2716-2725

Pieterse QD, Maas CP, ter Kuile MM, Lowik M, van Eijkeren MA, Trimbos JB, Kenter GG (2006) An observational longitudinal study to evaluate miction, defecation, and sexual function after radical hysterectomy with pelvic lymphadenectomy for early-stage cervical cancer. Int J Gynecol Cancer 16: $1119-1129$

Putta S, Andreyev HJ (2005) Faecal incontinence: a late side-effect of pelvic radiotherapy. Clin Oncol ( $R$ Coll Radiol) 17: 469-477

Rubin P, Constine LS, Fajardo LF, Phillips TL, Wasserman TH (1995) Overview. Late effects of normal tissues (LENT) scoring system. Int $J$ Radiat Oncol Biol Phys 31: $1041-1042$

Sinistrero G, Sismondi P, Rumore A, Zola P (1993) Analysis of complications of cervix carcinoma treated by radiotherapy using the Franco-Italian glossary. Radiother Oncol 26: 203-211 
Small Jr W, Mell LK, Anderson P, Creutzberg C, De Los Santos J, Gaffney D, Jhingran A, Portelance L, Schefter T, Iyer R, Varia M, Winter K, Mundt AJ (2008) Consensus guidelines for delineation of clinical target volume for intensity-modulated pelvic radiotherapy in postoperative treatment of endometrial and cervical cancer. Int J Radiat Oncol Biol Phys 71: $428-434$

Sprangers MA, Cull A, Bjordal K, Groenvold M, Aaronson NK (1993) The european organization for research and treatment of cancer. Approach to quality of life assessment: guidelines for developing questionnaire modules. EORTC Study Group on Quality of Life. Qual Life Res 2: 287-295

Steineck G, Bergmark K, Henningsohn L, al-Abany M, Dickman PW, Helgason A (2002) Symptom documentation in cancer survivors as a basis for therapy modifications. Acta Oncol 41: 244-252
Steineck G, Hunt H, Adolfsson J (2006) A hierarchical step-model for causation of bias-evaluating cancer treatment with epidemiological methods. Acta Oncol 45: 421-429

Trotti A, Colevas AD, Setser A, Rusch V, Jaques D, Budach V, Langer C, Murphy B, Cumberlin R, Coleman CN, Rubin P (2003) CTCAE v3.0: development of a comprehensive grading system for the adverse effects of cancer treatment. Semin Radiat Oncol 13: $176-181$

Waldenström AC, Olsson C, Wilderäng $U$, Dunberger G, Lind $H$, Al-Abany M, Palm A, vall-Lundqvist E, Johansson KA, Steineck G (2010) Pain and mean absorbed dose to the pubic bone after radiotherapy among gynecological cancer survivors. Int J Radiat Oncol Biol Phys 80: 1171-1180

This work is published under the standard license to publish agreement. After 12 months the work will become freely available and the license terms will switch to a Creative Commons Attribution-NonCommercial-Share Alike 3.0 Unported License. 